\title{
Biocontrol Activity and Primed Systemic Resistance by Compost Water Extracts Against Anthracnoses of Pepper and Cucumber
}

\author{
Mee Kyung Sang and Ki Deok Kim
}

First and second authors: Laboratory of Plant Disease and Biocontrol, College of Life Sciences and Biotechnology, Korea University, Seoul 136-713, Republic of Korea.

Accepted for publication 22 January 2011.

\section{ABSTRACT}

Sang, M. K., and Kim, K. D. 2011. Biocontrol activity and primed systemic resistance by compost water extracts against anthracnoses of pepper and cucumber. Phytopathology 101:732-740.

We investigated direct and indirect effects of compost water extracts (CWEs) from Iljuk-3, Iljuk-7, Shinong-8, and Shinong-9 for the control of anthracnoses caused by Colletotrichum coccodes on pepper and $C$. orbiculare on cucumber. All tested CWEs significantly $(P<0.05)$ inhibited in vitro conidial germination and appressorium formation of the fungal pathogens; however, DL- $\beta$-amino-n-butyric acid (BABA) failed to inhibit the conidial development of the pathogens. Direct treatments of the CWEs and BABA on pepper and cucumber leaves at 1 and 3 days before or after inoculation significantly $(P<0.05)$ reduced anthracnose severities; Iljuk-3, Shinong-9, and BABA for pepper and Iljuk-7 for cucumber had more protective activities than curative activities. In addition, root treatment of CWEs suppressed anthracnoses on the plants by the pathogens; however, CWE treatment on lower leaves failed to reduce the diseases on the upper leaves of the plants. The CWE root treatments enhanced not only the expression of the pathogenesis-related $(P R)$ genes CABPRl, CABGLU, CAChi2, CaPR-4, CAPO1, and CaPR-10 in pepper and $P R 1-1 a, P R-2, P R-3$, and $A P O X$ in cucumber but also the activity of $\beta-1,3$-glucanase, chitinase, and peroxidase and the generation of hydrogen peroxide in pepper and cucumber under pathogen-inoculated conditions. However, the CWE treatments failed to induce the plant responses under pathogen-free conditions. These results indicated that the CWEs had direct effects, reducing anthracnoses by $C$. coccodes on pepper leaves and $C$. orbiculare on cucumber leaves through protective and curative effects. In addition, CWE root treatments could induce systemic resistance in the primed state against pathogens on plant leaves that enhanced $P R$ gene expression, defense-related enzyme production, and hydrogen peroxide generation rapidly and effectively immediately after pathogen infection. Thus, the CWEs might suppress anthracnoses on leaves of both pepper and cucumber through primed (priming-mediated) systemic resistance.

Additional keywords: induced systemic resistance.
Plants can protect themselves from pathogen infections through defense responses induced by various biotic or abiotic triggers, including rhizobacteria, fungi, or certain compounds $(11,28$, 37,41). This phenomenon, known as induced systemic resistance (ISR), can cause local responses such as necrotic lesions that generate a signal, spreading into uninfected areas of the plants $(9,14)$. The ISR sometimes involves expression of pathogenesisrelated $(P R)$ genes; production of defense-related enzymes such as $\beta$-1,3-glucanase, chitinase, and peroxidase; or accumulation of phytoalexin $(14,29,38,44)$. This type of plant defense response against pathogen infection uses energy derived from limited resources allocated to development and survival of plants. Thus, plants may have evolved to save this energy in a "primed" state as part of induced resistance $(13,19)$. The primed plants induce the defense response immediately after pathogen infection, which leads not only to protection from pathogen infection but also to savings in terms of the energy cost for the defense (36). Priming in plants has been known to occur in DL- $\beta$-amino-n-butyric acid (BABA)-, benzothiadiazole (BTH)-, or acibenzolar-S-methyl (ASM, a BTH derivative)-mediated systemic acquired resistance (SAR) and rhizobacterium-mediated $\operatorname{ISR}(8,34,36)$ but little is known about composts or compost water extract (CWE)-mediated ISR.

Composts and CWEs from various organic wastes have been used to control various plant diseases $(15,18,31,35)$. For example,

Corresponding author: K. D. Kim; E-mail address: kidkim@ korea.ac.kr

doi:10.1094/PHYTO-10-10-0287

(c) 2011 The American Phytopathological Society they were used for the control of soilborne diseases, including those caused by Fusarium spp., Pythium spp., and Phytophthora spp. (2,20-22,31,35). These composts and CWEs have also been used in attempts to control airborne diseases, including gray mold of geranium caused by Botrytis cinerea, apple scab by Venturia inaequalis, wet rot of okra by Choanephora cucurbitarum, and powdery mildew of tomato by Oidium neolycopersi, through foliar application $(23,32,33,43)$. However, more researchers are interested in controlling foliar diseases with composts or organic amendments through ISR; for example, Septoria lycopersici on tomato, B. cinerea on cucumber and melon, and Colletotrichum orbiculare on cucumber $(20,42,45)$. According to Walters (39), plants continuously interact with various biotic (mycorrhiza, endophytes, rhizobacteria, and root-associated microbes) and abiotic (osmotic or proton stresses and mineral nutrition) environments in the field, and these environmental factors might induce resistance in plants against pathogenic or environmental stresses. In this regard, composts used in traditional agriculture practices might have such a trigger that could lead to ISR in plants.

In our previous study (31), we reported that root-drench treatment with CWEs suppressed root and leaf infections by $P$. capsici in pepper plants through either inhibition of pathogen development or ISR. In the root treatment with CWEs, we also observed that $P R$ genes, defense-related enzymes, and hydrogen peroxide in leaves were expressed or enhanced in pepper plants just after $P$. capsici infection. The expression or enhancement was not observed in uninoculated pepper leaves, although the plants were root-treated with CWE. These observations suggest that the CWE treatment primed the pepper plants to respond faster and stronger against pathogen infection. Furthermore, root treatment with 
CWEs could reduce disease severities caused by $C$. coccodes and C. orbiculare on leaves of pepper and cucumber through ISR. Thus, we were interested to determine whether CWE-mediated ISR in pepper and cucumber plants has biological activities in the primed state against $C$. coccodes and $C$. orbiculare similar to that observed in pepper leaves infected with $P$. capsici. These two airborne pathogens are responsible for anthracnoses of pepper and cucumber, which are important diseases causing serious reduction of pepper and cucumber production $(27,40)$. Therefore, in this study, we evaluated the indirect effects of root treatment of CWEs inducing the primed state of ISR in leaves against infections by $C$. coccodes on pepper and $C$. orbiculare on cucumber. In addition, we also examined the direct effects of CWE leaf treatment against pathogen infections on the plants to determine whether the effects were protective or curative.

\section{MATERIALS AND METHODS}

CWE, plant, and fungal inoculum. Four CWEs from Iljuk-3, Iljuk-7, Shinong-8, and Shinong-9 from our previous study were used in this study and prepared as described previously (31). Briefly, CWE was prepared from commercial compost facilities: Iljuk (Iljuk, Korea) = pig manure $(60 \%, \mathrm{vol} / \mathrm{vol})$, cow manure $(10 \%, \mathrm{vol} / \mathrm{vol})$, and sawdust (30\%, vol/vol); and Shinong (Pocheon, Korea $)=$ poultry manure $(70 \%$, vol/vol $)$, sawdust $(30 \%$, vol/vol $)$, and zeolite (trace). The composting conditions and physicochemical properties of the composts were described in our previous study (31). As previously determined, 10\% CWE (compost/ distilled water, wt/vol) was used for Iljuk-3 and Iljuk-7; 5\% CWE was used for Shinong-8 and Shinong-9. BABA (Sigma-Aldrich, St Louis) was used as a positive control at a concentration of 500 and $100 \mu \mathrm{g} / \mathrm{ml}$ for $C$. coccodes and C. orbiculare, respectively, in conidial development or leaf-spray tests; it was used at a concentration of 500 and $100 \mu \mathrm{g} / \mathrm{g}$ dry weight of potting mixture for $C$. coccodes and $C$. orbiculare, respectively, in root-drench tests. Sterile distilled water was used as a negative control.

Pepper plants (5-week-old 'Nockwang') and cucumber seedlings (2-week-old 'Baeknokdadagi') were prepared as described by Sang et al. (30) and Kwack et al. (24), respectively. Briefly, for pepper plants, germinated seeds were sown in 128-cell ( 3 by 3 by $5 \mathrm{~cm}$ ) plug trays filled with potting mixture (peat moss [Acadian Peat Moss Ltd., Lamègue, New Brunswick, Canada] and TKS2 [Floragard Product, Oldenburg, Germany], 1:1.5, vol/vol). These trays were then placed in a growth room with fluorescent light at $16 \mathrm{~h} /$ day at room temperature. Three weeks later, the seedlings were transplanted to $10-\mathrm{cm}$-diameter pots containing the same potting mixture and grown under the same conditions for 2 weeks. For cucumber seedlings, germinated seeds were sown in the same plug trays filled with the same potting mixture and grown under the same conditions for 2 weeks.

For inocula of pepper and cucumber plants, $C$. coccodes and $C$. orbiculare were cultured in potato dextrose agar (PDA) (Difco Laboratories, Detroit) in the dark for 10 and 7 days, respectively, at $28^{\circ} \mathrm{C}$. Conidia were harvested with sterile distilled water containing $0.03 \%$ ( $\mathrm{vol} / \mathrm{vol}$ ) Tween 20 and filtered through four layers of sterile cheesecloth to remove mycelial debris. Then, the conidial concentration of $C$. coccodes and $C$. orbiculare was adjusted to $5 \times 10^{5}$ conidia/ml using a hemacytometer for use of this study. Conidial suspensions without Tween 20 were also prepared at a pathogen concentration of $1 \times 10^{6}$ conidia/ml for observation of conidial germination and appressorium formation.

Inhibition of conidial germination and appressorium formation of $\boldsymbol{C}$. coccodes and $\boldsymbol{C}$. orbiculare. A drop (10\% [wt/vol] Iljuk-3 and Iljuk-7 and 5\% [wt/vol] Shinong-8 and Shinong-9, actual concentration) of the mixture $(1: 1, \mathrm{vol} / \mathrm{vol})$ of CWE $(20 \%$ [wt/vol] Iljuk-3 and Iljuk-7 and 10\% [wt/vol] Shinong-8 and Shinong-9) and the conidial suspensions of $C$. coccodes and $C$. orbiculare was incubated on a glass slide in the dark at $28^{\circ} \mathrm{C}$ as described in our previous study (31). BABA (positive control) and sterile distilled water (negative control) were used as controls. Twenty-four hours after incubation, conidial germination and appressorium formation were examined microscopically by evaluating $\approx 100$ conidia per observation (three times per replicate); then, germination (percent) among the observed conidia and appressorium formation (percent) among the germinated conidia were determined.

Biocontrol activity of CWE applied on pepper and cucumber leaves against anthracnose pathogens. Leaves of 5-weekold pepper plants and 2-week-old cucumber seedlings prepared as described above were directly sprayed with CWE, BABA, or sterile distilled water 1 and 3 days before or after inoculation with $C$. coccodes and $C$. orbiculare, respectively. For inoculation, the leaves were uniformly sprayed with the prepared conidial suspensions containing $0.03 \%$ (vol/vol) Tween 20 using an atomizer. At the same time, uninoculated plants were sprayed with sterile distilled water containing $0.03 \%$ (vol/vol) Tween 20. After inoculation, the plants were placed in a dew chamber with $100 \%$ relative humidity in the dark at $28^{\circ} \mathrm{C}$ for $24 \mathrm{~h}$. Then, the inoculated plants were transferred to a growth room with fluorescent light at $16 \mathrm{~h}$ /day at room temperature. Disease severity (percent) was expressed as diseased leaf area per leaf and evaluated on the third leaves of pepper plants and the first leaves of cucumber seedlings 5 days after inoculation using Matrox inspector version 2.2 as described by Kwack et al. (24).

ISR in pepper and cucumber leaves against anthracnose pathogens. To assess the ISR in pepper and cucumber leaves against $C$. coccodes and $C$. orbiculare, respectively, 5-week-old pepper plants and 2-week-old cucumber seedlings were rootdrenched with CWE $(1 \mathrm{ml} / \mathrm{g}$ dry weight of potting mixture), $\mathrm{BABA}$, or sterile distilled water. For inoculation, the plant leaves were uniformly sprayed with or without conidial suspensions of $C$. coccodes and $C$. orbiculare 3 and 5 days after treatment, respectively. Then, these plants were placed under the same conditions as described above. Disease severity (percent) on the third and first leaves of pepper and cucumber plants, respectively, was evaluated as described above.

In another experiment, 6-week-old pepper and 3-week-old cucumber plants were prepared for assessing ISR activity in the upper leaves of the plants following lower-leaf treatment with CWE. The third and first leaves only of the pepper and cucumber plants, respectively, were uniformly sprayed with CWE, BABA, or sterile distilled water. At 3 and 5 days after treatment, the fifth and second leaves only of the plants were inoculated with or without $C$. coccodes and $C$. orbiculare, respectively; these plants were placed under the same conditions as described above. Disease severity (percent) on the fifth and second leaves of pepper and cucumber plants, respectively, was evaluated as described above.

$P R$ gene, defense-related enzyme, and hydrogen peroxide in pepper and cucumber leaves against anthracnose pathogens. To evaluate $P R$ gene expression, defense-related enzyme production, and hydrogen peroxide $\left(\mathrm{H}_{2} \mathrm{O}_{2}\right)$ generation, 5-week-old pepper plants and 2-week-old cucumber seedlings were rootdrenched with CWE, BABA, or sterile distilled water 3 and 5 days before inoculation. For the $P R$ gene expression assay, the third and first leaves of pepper and cucumber plants were sampled $0,24,48$, and $72 \mathrm{~h}$ after inoculation with or without conidial suspensions of $C$. coccodes and $C$. orbiculare, respectively. These leaf samples were homogenized in liquid nitrogen using a mortar and a pestle; total RNA was then extracted from the homogenized leaf samples using Trizol Reagent (Invitrogen, Carlsbad, CA) according to the manufacturer's instructions. Reverse-transcriptase polymerase chain reaction (RT-PCR) with $18 \mathrm{~S}$ rRNA as an internal control (4) was performed as described by Sang et al. (31). The sequences of the gene-specific primer pairs for pepper were described in our previous work (31) and those for cucumber 
are listed in Table 1. The experiments were conducted twice with three replicate plants and produced similar results.

To assay defense-related enzymes such as $\beta$-1,3-glucanase, chitinase, and peroxidase, the same leaves of the treated pepper and cucumber plants were sampled 3 days after inoculation with or without the pathogens and then homogenized in liquid nitrogen using a mortar and a pestle. The $\beta$-1,3-glucanase activity was measured as the rate of reducing-sugar production from laminarin as a substrate (26). Chitinase activity was assayed by colorimetric determination of $\mathrm{N}$-acetylglucosamine using chitin oligomers as a substrate (1). Peroxidase activity was determined as the change in absorbance at $470 \mathrm{~nm} / \mathrm{min} / \mathrm{mg}$ of protein using guiacol as the hydrogen donor (12). Aliquots of the clear supernatants from the leaf extracts were used to determine protein contents by the Bradford method (3) using bovine serum albumin as a standard.

To measure $\mathrm{H}_{2} \mathrm{O}_{2}$ generation, the same leaves of the treated pepper and cucumber plants were sampled $0,6,12,24,36$, and $48 \mathrm{~h}$ after inoculation with or without $C$. coccodes and $C$. orbiculare. Quantification of $\mathrm{H}_{2} \mathrm{O}_{2}$ generation in the tissue samples was conducted as described in our previous work (31) based on the methods of Gay et al. (10).

Statistical analysis. Experiments were conducted twice with 3 replicates for conidial development tests, 10 replicates for ISR tests, and 4 replicates each for defense-related enzyme and $\mathrm{H}_{2} \mathrm{O}_{2}$ tests in which completely randomized designs were established. On the other hand, biocontrol activity tests on plants with CWE before and after inoculation were conducted twice with 10 replicates in which a split plot design was established, with CWEapplied day as the main plot factor and treatment as the subplot factor. Statistical analysis of data was conducted using the Statistical Analysis System (SAS Institute, Cary, NC). After confirming homogeneity of variances with Levene's test (25), data from repeated experiments were pooled. Contrast analysis for the data of biocontrol activity tests was conducted to compare the means between CWE-applied day before and after inoculation. Percent data of disease severity were statistically analyzed after arcsine square-root transformation. Analysis of variance was determined using the general linear model procedures and the means were separated by the least significant difference at $P<$ 0.05 .

\section{RESULTS}

Effects of CWE on in vitro conidial germination and appressorium formation of $C$. coccodes and $C$. orbiculare. CWE from Iljuk-3, Iljuk-7, Shinong-8, and Shinong-9 significantly $(P<0.05)$ inhibited rates of conidial germination and appressorium formation of both $C$. coccodes and $C$. orbiculare compared with the water controls (Table 2). However, BABA failed to inhibit the germination and appressorium formation of both anthracnose fungi (Table 2). The reduction in conidial germination of $C$. coccodes in response to CWE treatments was 28.7 to $40.4 \%$, while the reduction in appressorium formation was 23.4 to $79.2 \%$ compared with the water controls. Likewise, the reductions in conidial germination of $C$. orbiculare were 34.0 to
$67.3 \%$, while the reductions in appressorium formation were 47.9 to $69.4 \%$ compared with the water controls.

Effects of CWE directly applied on pepper and cucumber leaves against anthracnose pathogens. In pepper plants, direct treatment with CWE from Iljuk-3, Iljuk-7, Shinong-8, and Shinong-9 and BABA on the third leaves 1 and 3 days before or after inoculation with $C$. coccodes significantly $(P<0.05)$ reduced disease severity compared with the control water treatments (Table 3 ). As a positive control, BABA also significantly $(P<0.05)$ reduced disease severity on the pepper leaves. Similar results were observed on cucumber leaves inoculated with $C$. orbiculare. The direct treatments with all tested CWEs, except Iljuk-7 treatment 3 days after inoculation, and BABA on the first leaves of cucumber seedlings 1 and 3 days before or after inoculation with $C$. orbiculare also significantly $(P<0.05)$ reduced disease severity compared with control water treatments (Table 3 ).

Contrast analysis between CWE-applied day before and after inoculation showed that significant differences existed in CWE from Iljuk-3 $(P=0.0005)$ and Shinong-9 $(P<0.0001)$ and BABA $(P<0.0001)$ on pepper, and CWE from Iljuk-7 $(P<0.0001)$ on cucumber. However, significant $(P>0.05)$ differences were not observed in other treatments, including water treatments on both pepper and cucumber, by contrast analysis (Table 3 ).

Effects of CWE on ISR in pepper and cucumber leaves against anthracnose pathogens. Root-drench treatment with CWE from Iljuk-3, Iljuk-7, Shinong-8, and Shinong-9 and BABA (positive control) significantly $(P<0.05)$ reduced anthracnose

TABLE 2. Inhibition of in vitro conidial germination and appressorium formation of Colletotrichum coccodes and C. orbiculare by water extracts of composts (CWEs) Iljuk-3 (10\%, wt/vol), Iljuk-7 (10\%, wt/vol), Shinong-8 $(5 \%, \mathrm{wt} / \mathrm{vol})$, and Shinong-9 $(5 \%, \mathrm{wt} / \mathrm{vol})^{\mathrm{y}}$

\begin{tabular}{lcc}
\hline Fungus, treatment & Germination $(\%)^{\mathrm{z}}$ & Appressorium formation $(\%)$ \\
\hline C. coccodes & & \\
Water & $80.4 \pm 3.2 \mathrm{a}$ & $73.0 \pm 2.8 \mathrm{a}$ \\
BABA & $79.0 \pm 1.7 \mathrm{a}$ & $78.2 \pm 3.6 \mathrm{a}$ \\
Iljuk-3 & $50.6 \pm 1.5 \mathrm{~b}$ & $39.4 \pm 2.3 \mathrm{c}$ \\
Iljuk-7 & $57.3 \pm 5.1 \mathrm{~b}$ & $55.9 \pm 6.3 \mathrm{~b}$ \\
Shinong-8 & $47.9 \pm 6.0 \mathrm{~b}$ & $37.8 \pm 5.1 \mathrm{c}$ \\
Shinong-9 & $55.7 \pm 5.2 \mathrm{~b}$ & $15.2 \pm 2.2 \mathrm{~d}$ \\
C. orbiculare & & \\
Water & $70.0 \pm 2.4 \mathrm{a}$ & $63.5 \pm 4.4 \mathrm{a}$ \\
BABA & $59.5 \pm 7.1 \mathrm{a}$ & $59.3 \pm 9.7 \mathrm{a}$ \\
Iljuk-3 & $46.2 \pm 2.6 \mathrm{~b}$ & $19.4 \pm 2.0 \mathrm{~b}$ \\
Iljuk-7 & $22.9 \pm 1.3 \mathrm{c}$ & $30.2 \pm 3.4 \mathrm{~b}$ \\
Shinong-8 & $42.2 \pm 2.1 \mathrm{~b}$ & $21.4 \pm 3.6 \mathrm{~b}$ \\
Shinong-9 & $28.1 \pm 3.2 \mathrm{c}$ & $33.1 \pm 6.1 \mathrm{~b}$ \\
\hline
\end{tabular}

$y$ Values are the means of six replicates. Means \pm standard errors within columns followed by different letters are significantly different according to the least significant difference test at $P<0.05$. Arcsine square root-transformed data were used for statistical analysis of conidial germination and appressorium formation; however, untransformed data are presented.

${ }^{\mathrm{z}}$ Rates of germination among observed conidia and appressorium formation among germinated conidia of $C$. coccodes and $C$. orbiculare by the treatments with CWE, DL- $\beta$-amino butyric acid (BABA) (positive control), or sterile distilled water (negative control) were evaluated with $\approx 100$ conidia per observation (three times per replicate) after incubation at $28^{\circ} \mathrm{C}$ for $24 \mathrm{~h}$.

TABLE 1. Sequences of gene-specific primers used in the reverse-transcriptase polymerase chain reaction analysis for cucumber

\begin{tabular}{|c|c|c|c|c|}
\hline Gene & Specific class & $\begin{array}{c}\text { Accession } \\
\text { no. }^{\mathrm{y}}\end{array}$ & $5^{\prime}$ primer & $3^{\prime}$ primer \\
\hline PR1-1a & PR protein $1^{\mathrm{z}}$ & AF475286 & 5'-GTTGGGCCGATTGAGTGG-3' & 5'-GCATCTCACTTTGGCACATCC-3' \\
\hline$P R-2$ & $\beta$-1,3-Glucanase & $\mathrm{AB} 051372$ & 5'-GGTGACCGTCAGCGGG-3' & 5'-TTCCAACATTACAAGCTCTAAGA-3' \\
\hline$P R-3$ & Chitinase & DQ641104 & 5'-GCCTTACTCCATAACATCACTCC-3' & 5'-GATTTCGATATCGAGTCTGGCT-3' \\
\hline$A P O X$ & $\begin{array}{l}\text { Ascorbate } \\
\text { peroxidase }\end{array}$ & AY338957 & 5'-TCTTGCATGGCACTCTGCTG-3' & 5'-GCCCTACCCAATGTGTGACCACC-3' \\
\hline $18 \mathrm{~S}$ rRNA & 18S rRNA & AF206894 & 5'-CGGTCCGCCTATGGTGAGCACCGGTCGGC-3' & 5'-TTCTTGGATTTATGAAAGACGAACAACTGC-3' \\
\hline
\end{tabular}

\footnotetext{
y Accession numbers found at http://www.ncbi.nlm.nih.gov.
}

z $\mathrm{PR}=$ pathogenesis-related. 
severity caused by $C$. coccodes on the third leaves of pepper plants compared with water treatment (negative control) (Fig. 1A). The disease severity was reduced from 35.3 to $65.3 \%$ by CWE compared with water treatment. On the other hand, BABA produced the lowest disease severity, with $83.4 \%$ reduction compared with water treatment. Similar results were observed in cucumber plants root drenched with CWE and BABA (Fig. 1A). $\mathrm{CWE}$ and BABA treatments also significantly $(P<0.05)$ reduced

TABLE 3. Disease severity (\%) on third leaves of pepper and first leaves of cucumber treated with water extracts of composts (CWEs) Iljuk-3 (10\%, wt/vol), Iljuk-7 (10\%, wt/vol), Shinong-8 (5\%, wt/vol), and Shinong-9 $(5 \%, \mathrm{wt} / \mathrm{vol}) 1$ and 3 days before or after inoculation with Colletotrichum coccodes and C. orbiculare, respectively ${ }^{\mathrm{x}}$

\begin{tabular}{|c|c|c|c|c|c|c|}
\hline \multirow[b]{2}{*}{ Plant, treatment ${ }^{\mathrm{y}}$} & \multicolumn{2}{|c|}{ CWE applied before inoculation } & \multicolumn{2}{|c|}{ CWE applied after inoculation } & \multicolumn{2}{|c|}{ Before vs. after ${ }^{2}$} \\
\hline & 3 days & 1 day & 1 day & 3 days & $F$ & $P>F$ \\
\hline \multicolumn{7}{|c|}{ Pepper against $C$. coccodes } \\
\hline Water & $6.3 \pm 1.2 \mathrm{a}$ & $6.3 \pm 0.7 \mathrm{a}$ & $9.2 \pm 1.1 \mathrm{a}$ & $3.7 \pm 0.6 \mathrm{a}$ & 0.08 & 0.9524 \\
\hline Iljuk-3 & $2.0 \pm 0.8 \mathrm{c}$ & $0.4 \pm 0.1 \mathrm{~cd}$ & $3.7 \pm 0.6 \mathrm{~b}$ & $1.7 \pm 0.4 \mathrm{~b}$ & 13.37 & 0.0005 \\
\hline Iljuk-7 & $3.7 \pm 1.0 \mathrm{~b}$ & $0.7 \pm 0.1 \mathrm{bc}$ & $1.9 \pm 0.3 \mathrm{~cd}$ & $1.3 \pm 0.3 \mathrm{~b}$ & 0.03 & 0.8576 \\
\hline Shinong-8 & $0.9 \pm 0.2 \mathrm{c}$ & $1.3 \pm 0.4 \mathrm{~b}$ & $1.4 \pm 0.2 \mathrm{~d}$ & $1.1 \pm 0.2 \mathrm{~b}$ & 0.93 & 0.3370 \\
\hline Water & $2.0 \pm 0.3 \mathrm{a}$ & $1.6 \pm 0.3 \mathrm{a}$ & $1.5 \pm 0.3 \mathrm{a}$ & $2.1 \pm 0.3 \mathrm{a}$ & 0.03 & 0.8733 \\
\hline BABA & $0.3 \pm 0.1 \mathrm{c}$ & $0.3 \pm 0.1 \mathrm{~b}$ & $0.3 \pm 0.1 \mathrm{c}$ & $0.5 \pm 0.1 \mathrm{c}$ & 1.34 & 0.2501 \\
\hline Iljuk-3 & $1.0 \pm 0.3 b$ & $0.5 \pm 0.1 \mathrm{~b}$ & $0.9 \pm 0.2 b$ & $1.1 \pm 0.3 b c$ & 1.36 & 0.2463 \\
\hline Iljuk-7 & $0.3 \pm 0.1 \mathrm{c}$ & $0.3 \pm 0.1 \mathrm{~b}$ & $0.5 \pm 0.1 \mathrm{bc}$ & $1.4 \pm 0.3 \mathrm{ab}$ & 17.71 & $<0.0001$ \\
\hline Shinong-8 & $0.4 \pm 0.1 \mathrm{bc}$ & $0.3 \pm 0.1 \mathrm{~b}$ & $0.5 \pm 0.1 \mathrm{c}$ & $0.5 \pm 0.1 \mathrm{c}$ & 0.64 & 0.4277 \\
\hline Shinong-9 & $0.5 \pm 0.1 \mathrm{bc}$ & $0.4 \pm 0.2 \mathrm{~b}$ & $0.5 \pm 0.1 \mathrm{c}$ & $0.8 \pm 0.2 \mathrm{c}$ & 1.16 & 0.2848 \\
\hline
\end{tabular}

${ }^{x}$ Values are the means of 20 replicates and disease severity was evaluated 5 days after inoculation. No disease symptoms were observed in the uninoculated leaves of pepper and cucumber. Means \pm standard errors followed by different lowercase letters are significantly different within columns according to the least significant difference at $P<0.05$. Arcsine square root-transformed data were used for statistical analysis of disease severity; however, untransformed data are presented.

y Leaves of 5-week-old pepper plants and 2-week-old cucumber seedlings were directly sprayed with CWE, DL- $\beta$-amino butyric acid (BABA) (positive control), or sterile distilled water (negative control) 1 and 3 days before or after inoculation with C. coccodes and C. orbiculare, respectively.

${ }^{\mathrm{z}} F$ and $P$ values from contrast analysis between means of CWE-applied day before and after inoculation are presented.
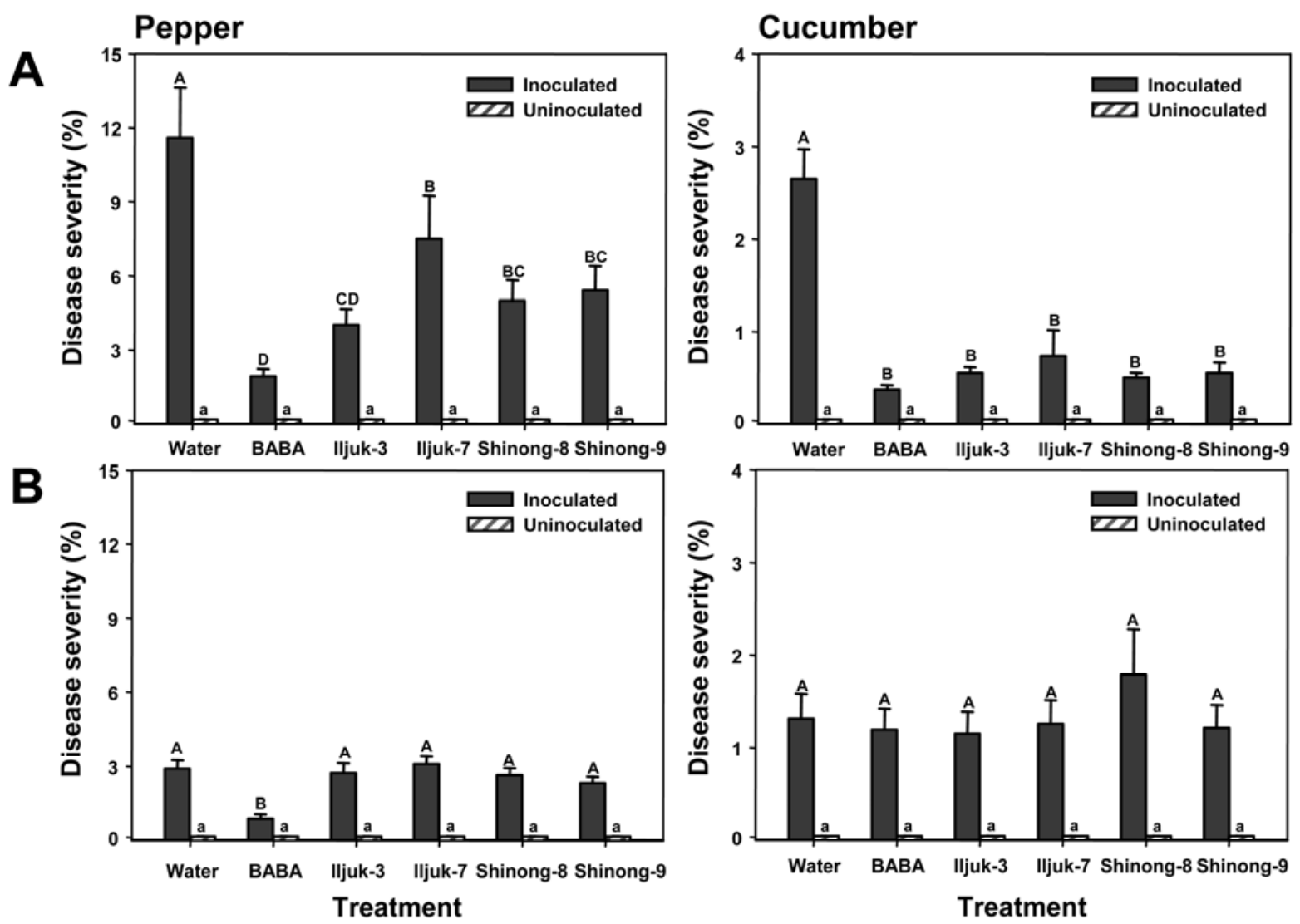

Fig. 1. A, Disease severity on the third leaves of 5-week-old pepper plants by Colletotrichum coccodes and the first leaves of 2-week-old cucumber seedling by $C$. orbiculare after root treatment with water extracts of composts (CWEs) Iljuk-3 (10\%, wt/vol), Iljuk-7 (10\%, wt/vol), Shinong-8 (5\%, wt/vol), and Shinong-9 (5\%, $\mathrm{wt} / \mathrm{vol}$ ); DL- $\beta$-amino butyric acid (BABA) (positive control); or sterile distilled water (negative control). B, Disease severity on the fifth (upper) leaves of 6-weekold pepper plants and second (upper) leaves of 3-week-old cucumber seedlings by the pathogens after the third (lower) and first (lower) leaves of the plants, respectively, were directly sprayed with the treatments. Pepper and cucumber plants were root-drenched or leaf-sprayed with the treatments and then inoculated with or without the pathogens 3 and 5 days after treatment, respectively. Disease severity was evaluated 5 days after inoculation. Each bar represents the standard errors of the means of 20 replicates. Different lowercase or uppercase letters on the bars indicate significant differences between treatments at $P<0.05$. 
anthracnose severity caused by $C$. orbiculare on the first leaves of cucumber compared with water treatment. The disease severity was reduced from 72.3 to $81.2 \%$ by CWE compared with water treatment. BABA also produced similar disease severity with $85.8 \%$ reduction compared with water treatment. Disease symptoms were not observed in the uninoculated leaves of pepper and cucumber plants (Fig. 1A).

Treatment of third (lower) leaves only of pepper plants with the CWE did not significantly $(P>0.05)$ reduce disease severity on the fifth (upper) leaves compared with water treatment when the fifth leaves only were inoculated by $C$. coccodes (Fig. 1B). However, BABA alone significantly $(P<0.05)$ reduced the disease severity on fifth leaves, with $69.5 \%$ reduction compared with the water treatment. In the case of cucumber seedlings, similar results were observed (Fig. 1B). The CWE and BABA did not significantly $(P>0.05)$ reduce disease severity on second (upper) leaves by $C$. orbiculare when the treatments were applied to the first (lower) leaves. Disease symptoms were not observed in the uninoculated leaves of pepper and cucumber plants (Fig. 1B).

Effects of CWE on $P R$ gene expression in pepper and cucumber leaves against anthracnose pathogens. On the inoculated third leaves of pepper plants root-drenched with CWE and BABA (positive control) treatments, the $P R$ genes, including $C A B P R 1$ (basic $P R$ protein 1), CABGLU ( $\beta$-1,3-glucanase), CAChi2 (class II chitinase), CaPR-4 (PR protein 4), CAPO1 (peroxidase), and $C a P R-10$ (PR protein 10), were expressed rapidly in certain treatments over sampling times compared with water treatment (negative control) (Fig. 2A). Similar results were observed in the inoculated first leaves of cucumber seedlings root drenched with the treatments (Fig. 2B). The expression of $P R$ genes, $P R 1-1 a$ (PR protein 1), $P R-2$ ( $\beta$-1,3-glucanase), $P R-3$ (chitinase), and $A P O X$ (ascorbate peroxidase) was also detected with certain treatments compared with water treatment. However, expression of PRI-1a was not detected in the Iljuk-7 treatment (Fig. 2B). In addition, uninoculated leaves of pepper and cucumber plants did not express the $P R$ genes regardless of treatments.

Effects of CWE on defense-related enzyme production in pepper and cucumber leaves against anthracnose pathogens. Quantitative increases in the activities of defense-related enzymes such as $\beta$-1,3-glucanase, class II chitinase, and peroxidase were observed in leaves of pepper and cucumber plants root drenched with CWE and BABA (positive control) 3 days after inoculation with $C$. coccodes and $C$. orbiculare compared with water treatments (negative control) (Fig. 3). In pepper leaves inoculated with $C$. coccodes, all CWEs and BABA significantly $(P<0.05)$ increased the activities of class II chitinase and peroxidase. However, Iljuk-3 and BABA only significantly $(P<0.05)$ increased $\beta$ 1,3-glucanase activity compared with the water treatment (Fig. 3). On the other hand, in cucumber leaves inoculated with $C$. orbiculare, certain CWEs only increased one or two of the defenserelated enzymes compared with water treatments. For example, Iljuk-3 significantly $(P<0.05)$ increased $\beta$-1,3-glucanase activity, Iljuk-7 increased chitinase and peroxidase activities, and Shinong-8 increased peroxidase activity. However, Shinong-9 failed to increase any tested enzyme activities. Likewise, BABA increased all tested enzyme activities in the inoculated cucumber leaves, as observed in the pepper leaves (Fig. 3). However, CWE and BABA treatments did not significantly $(P>0.05)$ affect the enzyme activities, except for peroxidase activity by Iljuk-7 when pepper and cucumber leaves were not inoculated (Fig. 3).

Effects of CWE on $\mathrm{H}_{2} \mathrm{O}_{2}$ generation in pepper and cucumber leaves against anthracnose pathogens. In pepper plants, the generation of $\mathrm{H}_{2} \mathrm{O}_{2}$ was increased greatly in third leaves of plants root drenched with all treatments at 6 to $48 \mathrm{~h}$ after inoculation with $C$. coccodes compared with uninoculated leaves (Fig. 4A). The CWE and BABA treatments significantly $(P<0.05)$ induced
A

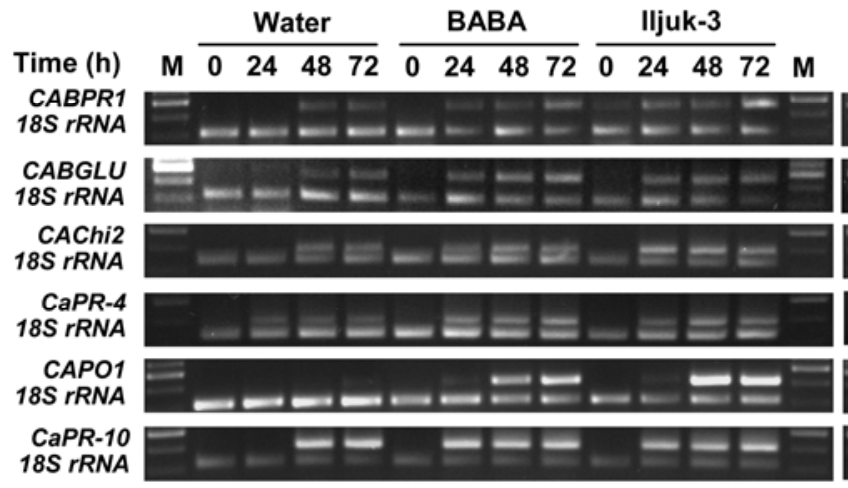

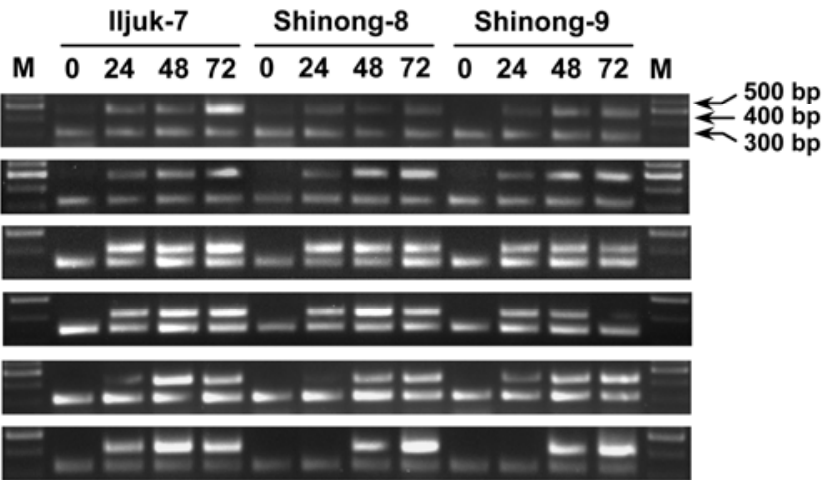
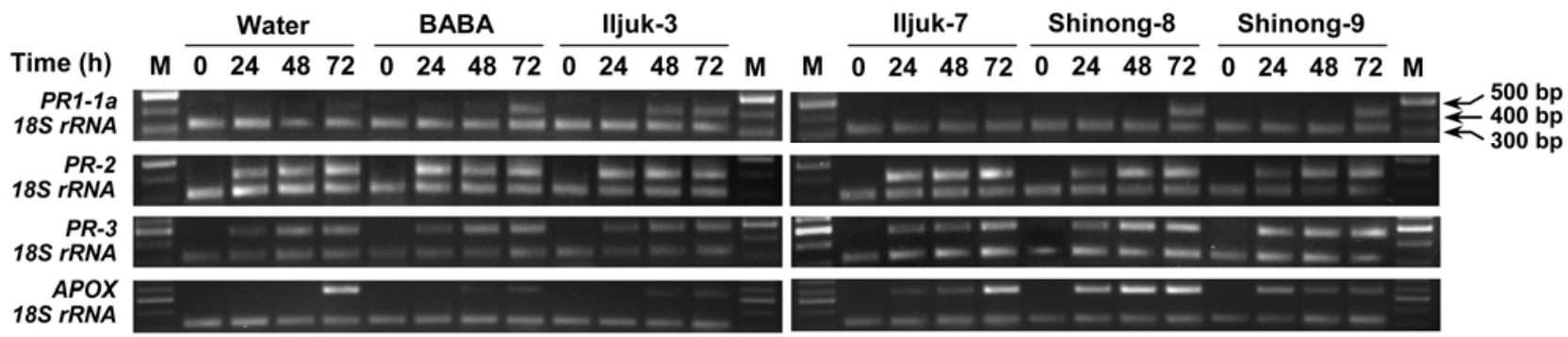

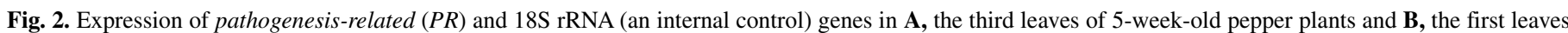

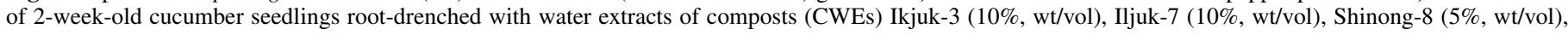

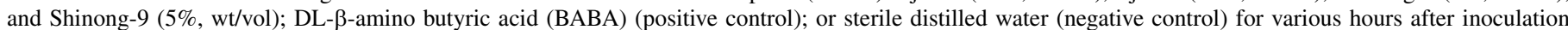

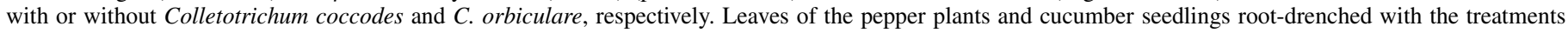

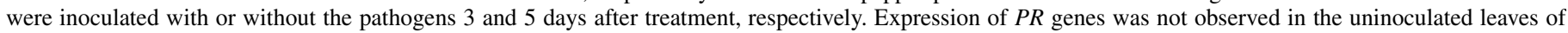

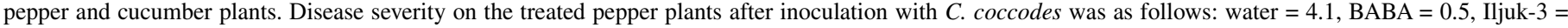

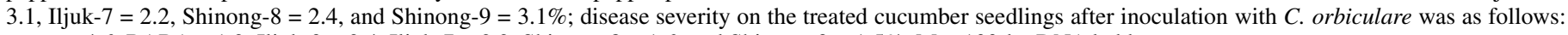
water $=4.6$, BABA $=1.2$, Iljuk-3 $=2.4$, Iljuk-7 = 2.2, Shinong- $8=1.6$, and Shinong-9 $=1.5 \%$. M = 100-bp DNA ladder. 
higher levels of $\mathrm{H}_{2} \mathrm{O}_{2}$ at 12 to $48 \mathrm{~h}$ in inoculated leaves compared with water treatments (Fig. 4A). Similar results were observed in cucumber inoculated with $C$. orbiculare (Fig. 4B). The $\mathrm{H}_{2} \mathrm{O}_{2}$ generation was greatly enhanced in first leaves of cucumber seedlings root drenched with all treatments at 6 to $48 \mathrm{~h}$ after inoculation compared with the uninoculated leaves. Moreover, the CWE and BABA treatments significantly $(P<0.05)$ induced higher levels of $\mathrm{H}_{2} \mathrm{O}_{2}$ than water treatments in the inoculated leaves at 12 to $48 \mathrm{~h}$ after inoculation (Fig. 4B). In both pepper and cucumber, the levels of $\mathrm{H}_{2} \mathrm{O}_{2}$ reached a maximum at $24 \mathrm{~h}$ after inoculation and then decreased gradually (Fig. 4). However, $\mathrm{H}_{2} \mathrm{O}_{2}$ generation was not significantly $(P>0.05)$ different in the uninoculated leaves over time regardless of the treatments (Fig. 4).

\section{DISCUSSION}

In our previous study, a heat-stable chemical present in CWE from Iljuk-3, Iljuk-7, Shinong-8, and Shinong-9 effectively inhibited root and foliar infections by $P$. capsici in pepper plants (31). These inhibitions resulted from direct effects on pathogen development, as well as from indirect effects on pathogen infection through ISR. Therefore, we further investigated whether
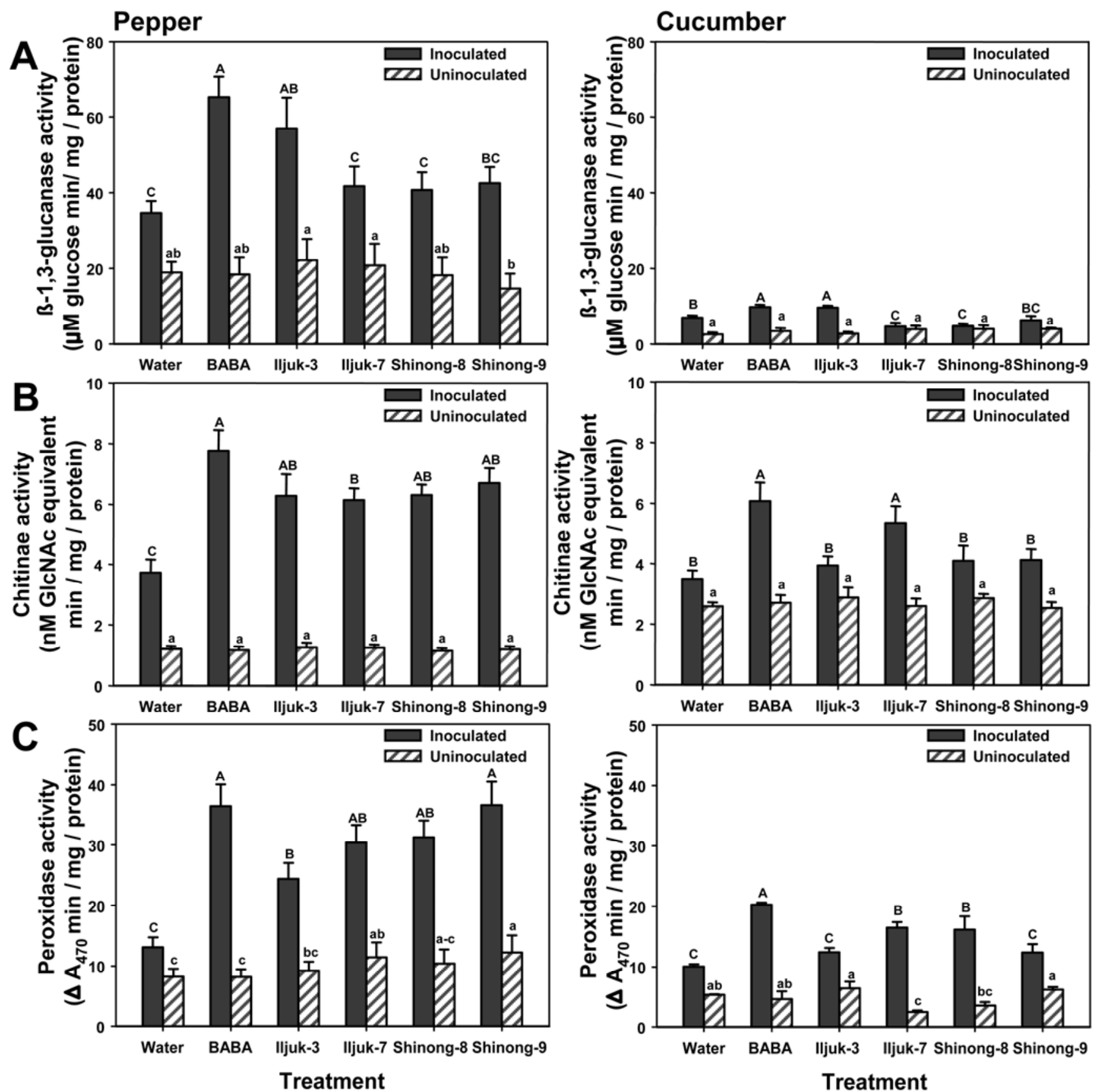

Fig. 3. A, $\beta-1,3$-Glucanase; B, chitinase; and $\mathbf{C}$, peroxidase activities in the third leaves of 5-week-old pepper plants and the first leaves of 2-week-old cucumber seedlings root-drenched with water extracts of composts (CWEs) Iljuk-3 (10\%, wt/vol), Iljuk-7 (10\%, wt/vol), Shinong-8 (5\%, wt/vol), and Shinong-9 (5\%, $\mathrm{wt} / \mathrm{vol}$ ); DL- $\beta$-amino butyric acid (BABA) (positive control); and sterile distilled water (negative control) 3 days after inoculation with or without Colletotrichum coccodes and $C$. orbiculare, respectively. Leaves of the pepper and cucumber plants were inoculated with or without the pathogens 3 and 5 days after treatment, respectively. Each bar represents the standard error of the mean of eight replicates. Different lowercase or uppercase letters on the bars indicate significant differences between treatments at $P<0.05$. Disease severity on the treated pepper plants after inoculation with $C$. coccodes was as follows: water $=4.1$, BABA $=$ 0.5 , Iljuk-3 $=3.1$, Iljuk-7 $=2.2$, Shinong- $8=2.4$, and Shinong- $9=3.1 \%$; disease severity on the treated cucumber seedlings after inoculation with $C$. orbiculare was as follows: water $=4.6, \mathrm{BABA}=1.2$, Iljuk- $3=2.4$, Iljuk- -2.2 , Shinong- $8=1.6$, and Shinong-9 $=1.5 \%$. 
CWE could have direct biocontrol activity and induce ISR in the priming state against anthracnoses of pepper and cucumber caused by $C$. coccodes and $C$. orbiculare, respectively. The results from this study demonstrated that the tested CWEs had direct biocontrol activities with curative and protective effects and induced ISR in leaves of pepper and cucumber with the primed state against the pathogens.

The tested CWEs had in vitro inhibitory activity against conidial germination and appressorium formation of the anthracnose fungi $C$. coccodes and $C$. orbiculare. This result was similar to those observed in our previous study (31) (i.e., direct effects on zoospore germination, germ tube elongation, and mycelial growth of $P$. capsici.) This implies that, in the in vitro inhibition, CWEs had a broad-spectrum activity against not only the soilborne oomycete pathogen $P$. capsici but also the airborne fungal pathogens $C$. coccodes and $C$. orbiculare. From these observations, we designed experiments to test the effects of CWE against $C$. coccodes and $C$. orbiculare on pepper and cucumber leaves when the CWE was directly applied on the leaves before or after
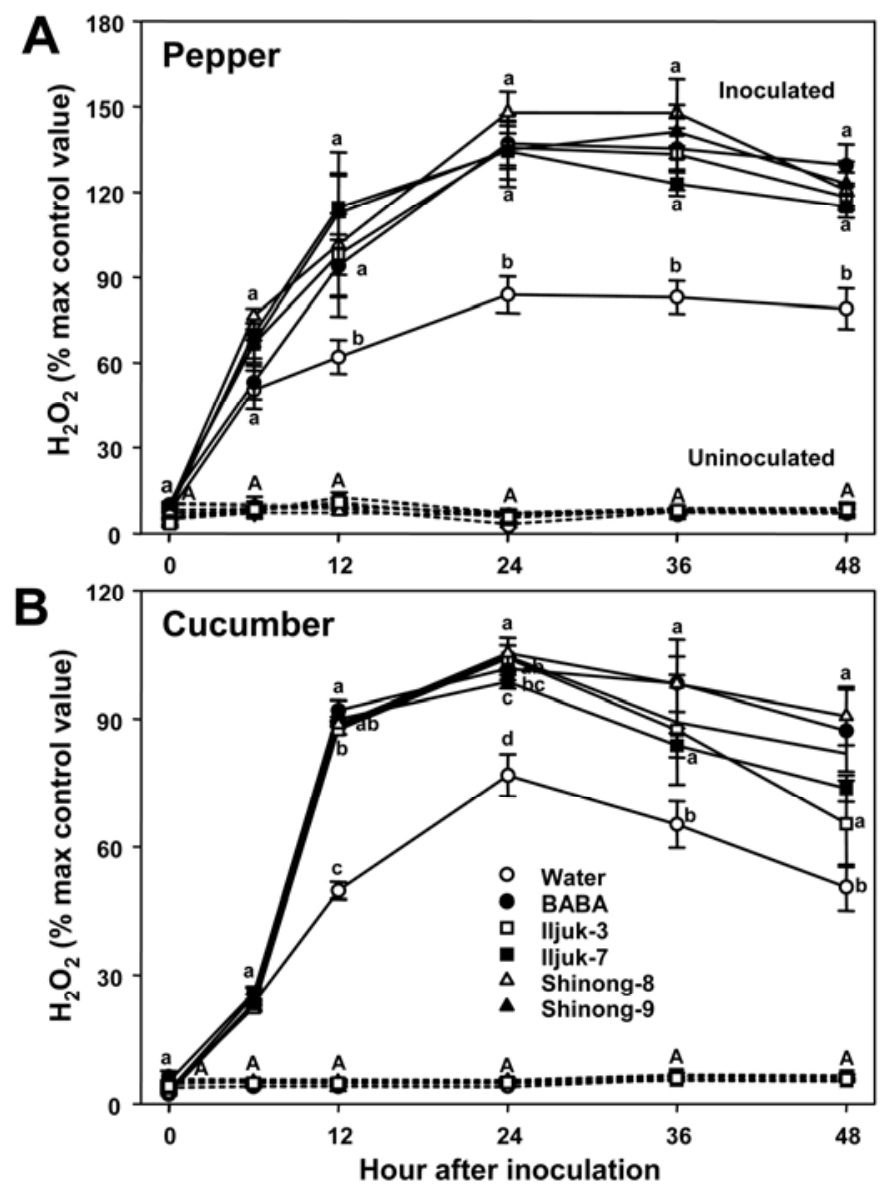

Fig. 4. Quantification of $\mathrm{H}_{2} \mathrm{O}_{2}$ generation in A, the third leaves of 5-week-old pepper plants and $\mathbf{B}$, the first leaves of 2-week-old cucumber seedlings rootdrenched with water extracts of composts (CWEs) Iljuk-3 (10\%, wt/vol), Iljuk-7 (10\%, wt/vol), Shinong-8 (5\%, wt/vol), and Shinong-9 (5\%, wt/vol); DL- $\beta$-amino butyric acid (BABA) (positive control); or sterile distilled water (negative control) at various hours after inoculation with or without Colletotrichum coccodes and $C$. orbiculare, respectively. Leaves of the pepper and cucumber plants were inoculated with or without the pathogens 3 and 5 days after treatment, respectively. Each bar represents the standard errors of the means of eight replicates. Different lowercase or uppercase letters at a given time indicate significant differences between treatments at $P<0.05$. Disease severity on the treated pepper plants after inoculation with $C$. coccodes was as follows: water $=11.6, \mathrm{BABA}=1.9$, Iljuk-3 $=4.0$, Iljuk-7 $=7.5$, Shinong- $8=$ 5.0 , and Shinong- $9=5.4 \%$; disease severity on the treated cucumber seedlings after inoculation with $C$. orbiculare was as follows: water $=2.6, \mathrm{BABA}=0.4$, Iljuk-3 $=0.5$, Iljuk-7 $=0.7$, Shinong- $8=0.5$, and Shinong- $9=0.5 \%$. inoculation with the pathogens. As a result, the direct CWE treatments on the leaves of both pepper and cucumber reduced disease severity whether or not they were applied before or after inoculation. These indicate that the CWEs had direct biocontrol activity against the airborne fungal pathogens on the plants with preventive or curative activities. In addition, Iljuk-3, Shinong-9, and BABA for pepper and Iljuk-7 for cucumber had more protective activities than curative activities according to our contrast analysis between CWE-applied days before and after inoculation. In a study for control of tomato diseases with compost teas, Koné et al. (23) reported similar results. They observed that compost teas had inhibitory activity against mycelial growth of Alternaria solani, B. cinerea, and $P$. infestans, and the spray of the compost teas resulted in foliar disease suppression on tomato plants. Interestingly, in our current study, BABA, as an ISR inducer, failed to inhibit the in vitro development of fungal conidia as observed by Hong et al. (16) in the C. coccodes-pepper system; however, direct treatment with BABA reduced the disease severity on the plant leaves. These phenomena might be explained by the possibility that reduction of disease severity resulted from induced resistance in leaves rather than direct suppression of the pathogens. ISR by BABA could occur because a large portion of the sprayed BABA could be taken up into plant surface tissues and prolonged for days $(5,6)$.

We found that, in addition to the observed protective or curative effects by CWE against anthracnose pathogens, root treatment with CWE suppressed foliar diseases by $C$. coccodes on pepper and $C$. orbiculare on cucumber as shown in our previous study (31); however, CWE treatment on lower leaves failed to reduce the diseases on upper leaves of the plants. These results indicate that CWE might act as an ISR inducer to trigger systemic resistance in plant leaves against pathogens in the root treatment but not in lower-leaf treatment. The failure of lower-leaf treatment of CWE to induce ISR may occur because the plant leaves might not recognize, absorb, or translocate the CWE inducer from the lower to upper leaves. Earlier, Jakab et al. (17) found that BABA could be taken up by roots or leaves following rapid translocation to younger parts of shoots through the xylem in Arabidopsis. Consequently, they observed that this was positively related with disease reduction. Unlike CWE, BABA treatment on lower leaves of pepper plants reduced anthracnose severity in upper leaves, which could result from ISR as observed by Hong et al. (16).

The root treatment with CWE in this study rapidly activated the expression of the $P R$ genes $C A B P R 1$ (basic $P R$ protein 1), $C A B G L U$ ( $\beta$-1,3-glucanase), $C A C h i 2$ (class II chitinase), CaPR-4 (PR protein 4), CAPOI (peroxidase), and CaPR-10 (PR protein $10)$ in $C$. coccodes-infected pepper and $P R-1 a$ (PR protein 1), $P R$ 2 ( $\beta$-1,3-glucanase), $P R-3$ (chitinase), and $A P O X$ (ascorbate peroxidase) in $C$. orbiculare-infected cucumber. The treatments enhanced the activities of defense-related enzymes, including $\beta$ 1,3-glucanase, chitinase, and peroxidase, as well as $\mathrm{H}_{2} \mathrm{O}_{2}$ generation. The $P R$ gene expression, enhanced enzyme production, and $\mathrm{H}_{2} \mathrm{O}_{2}$ generation could result in increased plant defenses against infection by $C$. coccodes in pepper and $C$. orbiculare in cucumber. However, when the pathogens were not inoculated, CWE did not activate defense responses such as enzyme and $\mathrm{H}_{2} \mathrm{O}_{2}$ production or $P R$ gene expression in the plants. Thus, these results indicate that CWE triggers ISR only when the pathogens contact and initiate infection of the plants. Furthermore, these findings imply that the CWE tested in this study induced priming at low energy cost to the plants, allowing the defense responses to activate rapidly and effectively after the pathogens' contact the plants. Recently, several researchers observed that priming was associated with different types of induced resistances, including SAR or ISR $(7,8)$. In this regard, Van Hulten et al. (36) examined the costs and benefits between BABA- or BTH-induced priming and direct defense in the absence and presence of plant pathogens in Arabidopsis. They observed that primed plants did not activate 
defense responses under pathogen-free conditions but, rather, activated them after pathogen infection. Thus, they concluded that the benefits (protection from pathogen infection) of primingmediated resistance exceeded the costs under disease occurrence. In this study, CWE triggered induced resistance, including $P R$ gene expression, in pepper and cucumber plants just after pathogen infection; CWE enhanced the generation of $\mathrm{H}_{2} \mathrm{O}_{2}$ and activities of defense-related enzymes such as $\beta$-1,3-glucanase, peroxidase, and chitinase. However, the CWE did not induce plant defense responses under pathogen-free conditions. Thus, these results suggest that CWE might induce priming-mediated resistance at low cost, as suggested by Van Hulten et al. (36).

Taken together, these results indicate that the CWE tested in this study inhibited in vitro conidial germination and appressorium formation of $C$. coccodes and C. orbiculare; direct CWE treatment reduced anthracnose severities by the pathogens on pepper and cucumber leaves with protective and curative effects. In addition, the CWE induced systemic resistance with a primed state against the pathogens on the plant leaves, which enhanced the $P R$ gene expression, defense-related enzyme production, and $\mathrm{H}_{2} \mathrm{O}_{2}$ generation rapidly and effectively just after pathogen infections. Thus, the CWE might suppress anthracnoses on pepper and cucumber through primed (priming-mediated) systemic resistance.

\section{ACKNOWLEDGMENTS}

This study was conducted with the support of the Korean University Grant and the Cooperative Research Program for Agricultural Science \& Technology Development (project no. 200901OFT 102967499), Rural Development Administration, Republic of Korea. We thank E. N. Kim for technical help in enzyme assays, H. W. Jung for valuable comments, and J. K. Hong and H. W. Choi for reviewing this manuscript.

\section{LITEATURE CITED}

1. Abeles, F. B., Bosshart, R. P., Forrence, L. E., and Habig, W. H. 1970. Preparation and purification of glucanase and chitinase from bean leaves. Plant Physiol. 47:129-134.

2. Bailey, K. L., and Lazarovits, G. 2003. Suppressing soil-borne diseases with residue management and organic amendments. Soil Tillage Res. 72:169-180.

3. Bradford, M. M. 1976. A rapid and sensitive method for the quantitation of microgram quantities of protein utilizing the principle of protein-dye binding. Anal. Biochem. 72:248-254.

4. Choi, H. W., Kim, Y. J., Lee, S. C., Hong, J. K., and Hwang, B. K. 2007. Hydrogen peroxide generation by the pepper extracellular peroxidase $\mathrm{CaPO} 2$ activates local and systemic cell death and defense response to bacterial pathogens. Plant Physiol. 145:890-904.

5. Cohen, Y. 2002. $\beta$-Aminobutyric acid-induced resistance against plant pathogens. Plant Dis. 86:448-457.

6. Cohen, Y., and Gisi, U. 1994. Systemic translocation of ${ }^{14}$ C-DL-3aminobutyric acid in tomato plants in relation to induced resistance against Phytophthora infestans. Physiol. Mol. Plant Pathol. 45:441-456.

7. Conrath, U., Beckers, G. J. M., Flors, V., García-Agustín, P., Jakab, G., Mauch, F., Newman, M.-A., Pieterse, C. M. J., Poinssot, B., Pozo, M. J., Pugin, A., Schaffrath, U., Ton, J., Wendehenne, D., Zimmerli, L., and Mauch-Mani, B. 2006. Priming: Getting ready for battle. Mol. PlantMicrobe Interact. 19:1062-1071.

8. Conrath, U., Pieterse C. M. J., and Mauch-Mani, B. 2002. Priming in plant-pathogen interactions. Trends Plant Sci. 7:210-216.

9. Dean, R. A., and Kuc, J. 1985. Induced systemic protection in plants. Trends Biotechnol. 3:125-129.

10. Gay, C., Collins, J., and Gebicki, J. M. 1999. Determination of iron in solutions with the ferric-xylenol orange complex. Anal. Biochem. 273:143-148.

11. Hammerschmidt, R. 1999. Induced disease resistance: how do induced plants stop pathogens? Physiol. Mol. Plant Pathol. 55:77-84.

12. Hammerschmidt, R., Nuckles, E. M., and Kuc, J. 1982. Association of enhanced peroxidase activity with induced systemic resistance of cucumber to Colletotrichum lagenarium. Physiol. Plant Pathol. 20:73-82.

13. Heil, M. 2002. Ecological costs of induced resistance. Curr. Opin. Plant Biol. 5:345-350.

14. Heil, M., and Bostock, R. M. 2002. Induced systemic resistance (ISR) against pathogens in the context of induced plant defences. Ann. Bot. 89:503-512.
15. Hoitink, H. A. J., and Boehm, M. J. 1999. Biocontrol within the context of soil microbial communities: a substrate-dependent phenomenon. Annu. Rev. Phytopathol. 37:427-446.

16. Hong, J. K., Hwang, B. K., and Kim, C. H. 1999. Induction of local and systemic resistance to Colletotrichum coccodes in pepper plants by DL- $\beta$ amino-n-butyric acid. J. Phytopathol. 147:193-198.

17. Jakab, G., Cottier, V. Toquin, V., Rigoli, G., Zimmerli, L., Métraux, J.-P., and Mauch-Mani, B. 2001. $\beta$-Aminobutyric acid-induced resistance in plants. Eur. J. Plant Pathol. 107:29-37.

18. Joshi, D., Hooda, K. S., Bhatt, J. C., Mina, B. L., and Gupta, H. S. 2009. Suppressive effects of composts on soil-borne and foliar diseases of French bean in the field in the western Indian Himalayas. Crop Prot. 28:608-615.

19. Katz, V. A., Thulke, O. U., and Conrath, U. 1998. A benzothiadiazole primes parsley cells for augmented elicitation of defense responses. Plant Physiol. 117:1333-1339.

20. Kavroulakis, N., Ehaliotis, C., Ntougias, S., Zervakis, G. I., and Papadopoulou, K. K. 2005. Local and systemic resistance against fungal pathogens of tomato plants elicited by a compost derived from agricultural residues. Physiol. Mol. Plant Pathol. 66:163-174.

21. Kim, K. D., Nemec, S., and Musson, G. 1997. Control of Phytophthora root and crown rot of bell pepper with composts and soil amendments in the greenhouse. Appl. Soil Ecol. 5:169-179.

22. Kim, K. D., Nemec, S., and Musson, G. 1997. Effects of composts and soil amendments on soil microflora and Phytophthora root and crown rot of bell pepper. Crop Prot. 16:165-172.

23. Koné, S. B., Dionne, A., Tweddell, R. J., Antoun, H., and Avis, T. J. 2010. Suppressive effect of non-aerated compost teas on foliar fungal pathogens of tomato. Biol. Control 52:167-173.

24. Kwack, M. S., Kim, E. N., Lee, H., Kim, J.-W., Chun, S.-C., and Kim, K. D. 2005. Digital image analysis to measure lesion area of cucumber anthracnose by Colletotrichum orbiculare. J. Gen. Plant Pathol. 71:418-421.

25. Levene, H. 1960. Contributions to Probability and Statistics: Essays in Honor of Harold Hotelling. Stanford University Press, Stanford, CA.

26. Nelson, T. E., Scaletti, J. V., Smith, F., and Kirkwood, S. 1963. The use of enzymes in structural studies on polysaccharides. I. The mode of attack of a $\beta$-D- $(1 \rightarrow 3)$-glucanase on laminarin. Can. J. Chem. 41:1671-1678.

27. Oh, I.-S., In, M.-S., Woo, I.-S., Lee, S.-K., and Yu, S.-H. 1988. Anthracnose of pepper seedling caused by Colletotrichum coccodes (Wallr.) Hughes. Korean J. Mycol. 16:151-156.

28. Oostendorp, M., Kunz, W., Dietrich, B., and Staub, T. 2001. Induced disease resistance in plants by chemicals. Eur. J. Plant Pathol. 107:19-28.

29. Park, K. S., and Kloepper, J. W. 2000. Activation of PR-1a promoter by rhizobacteria that induce systemic resistance in tobacco against Pseudomonas syringae pv. tabaci. Biol. Control 18:2-9.

30. Sang, M. K., Chun, S.-C., and Kim, K. D. 2008. Biological control of Phytophthora blight of pepper by antagonistic rhizobacteria selected from a sequential screening procedure. Biol. Control 46:424-433.

31. Sang, M. K., Kim, J.-G., and Kim, K. D. 2010. Biocontrol activity and induction of systemic resistance in pepper by compost water extracts against Phytophthora capsici. Phytopathology 100:774-783.

32. Scheuerell, S. J., and Mahaffee, W. F. 2006. Variability associated with suppression of gray mold (Botrytis cinerea) on geranium by foliar applications of nonaerated and aerated compost teas. Plant Dis. 90:12011208.

33. Siddiqui, Y., Meon, S., Ismail, R., and Rahmani, M. 2009. Bio-potential of compost tea from agro-waste to suppress Choanephora cucurbitarum L. the causal pathogen of wet rot of okra. Biol. Control 49:38-44.

34. Van der Ent, S., van Hulten, M., Pozo, M. J., Czechowski, T., Udvardi, M. K., Pieterse, C. M. J., and Ton, J. 2009. Priming of plant innate immunity by rhizobacteria and $\beta$-aminobutyric acid: differences and similarities in regulation. New Phytol. 183:419-431.

35. Van der Gaag, D. J., van Noort, F. R., Stapel-Cuijpers, L. H. M., de Kreij, C., Termorshuizen, A. J., van Rijn, E., Zmora-Nahum, S., and Chen, Y. 2007. The use of green waste compost in peat-based potting mixtures: fertilization and suppressiveness against soilborne disease. Sci. Hortic. 114:289-297.

36. Van Hulten, M., Pelser, M., van Loon, L. C., Pieterse, C. M. J., and Ton, J. 2006. Costs and benefits of priming for defense in Arabidopsis. Proc. Natl. Acad. Sci. USA 103:5602-5607.

37. Van Loon, L. C., Bakker, P. A. H. M., and Pieterse, C. M. J. 1998. Systemic resistance induced by rhizosphere bacteria. Annu. Rev. Phytopathol. 36:453-483.

38. Van Loon, L. C., Rep, M., and Pieterse, C. M. J. 2006. Significance of inducible defense-related proteins in infected plants. Annu. Rev. Phytopathol. 44:135-162.

39. Walters, D. R. 2009. Are plants in the field already induced? Implications for practical disease control. Crop Prot. 28:459-465.

40. Wasilwa, L. A, Correll, J. C, Morelock, T. E., and McNew, R. E. 1993. Reexamination of races of the cucurbit anthracnose pathogen Colletot- 
richum orbiculare. Phytopathology 83:1190-1198.

41. Wei, G., Kloepper, J. W., and Tuzun, S. 1996. Induced systemic resistance to cucumber disease and increased plant growth by plant growthpromoting rhizobacteria under field conditions. Phytopathology 86:221224.

42. Yogev, A., Raviv, M., Hadar, Y., Cohen, R., Wolf, S., Gil, L., and Katan, J. 2010. Induced resistance as a putative component of compost suppressiveness. Biol. Control 54:46-51.

43. Yohalem, D. S., Nordheim, E. V., and Andrews, J. H. 1996. The effect of water extracts of spent mushroom compost on apple scab in the field. Phytopathology 86:914-922.

44. Zhang, S., Moyne, A.-L., Reddy, M. S., and Kloepper, J. W. 2002. The role of salicylic acid in induced systemic resistance elicited by plant growth-promoting rhizobacteria against blue mold of tobacco. Biol. Control 25:288-296.

45. Zhang, W., Han, D. Y., Dick, W. A., Davis, K. R., and Hoitink, H. A. J. 1998. Compost and compost water extract-induced systemic acquired resistance in cucumber and Arabidopsis. Phytopathology 88:450-455. 